\title{
Prevention and Control of Production Limiting Goat Diseases on Small Farms
}

\author{
Marshall RW*, Gebrelul S and Adams C \\ Southern University Agricultural Research and Extension Center, College of Agriculture, Baton Rouge, LA 70813, \\ Louisiana, United States
}

*Corresponding author: Marshall RW, Southern University Agricultural Research and Extension Center, College of Agriculture, Baton Rouge, LA 70813, Louisiana, United States, Fax: (225)771-4464, Tel: (225)7710252, E-mail: renita_marshall@suagcenter.com

Citation: Marshall RW, Gebrelul S, Adams C (2017) Prevention and Control of Production Limiting Goat Diseases on Small Farms. J Vet Sci Anim Husb 5(1): 102. doi: 10.15744/2348-9790.5.102

Received Date: November 09, 2016 Accepted Date: February 24, 2017 Published Date: February 27, 2017

\begin{abstract}
This article was written in support of development of new strategies to control economically important diseases of goats, and advance the body of knowledge of agricultural professionals and small farmers on disease surveillance and biosecurity for farm operations. The goat industry has been looking for more effective ways to alleviate health problems for a long time. There is an evolving need for scientists, agricultural professionals with expertise in small ruminants, along with the input from goat producers, to develop strategies tailored for specific disease prevalence that affects sustainable small ruminant productions.
\end{abstract}

Keywords: Goat production; Disease surveillance; Biosecurity; Investigation; Health

\section{Introduction}

The US livestock industry generates $\$ 100$ billion annually. Serious economic impacts are expected if animal diseases are introduced, suspected or prevalent. Each small ruminant herd's productivity is directly impacted by the health of the animals in the operation. Not only can diseases reduce efficiency, illness outbreaks are detrimental to animal welfare and consumer confidence. Control measures largely depend on the knowledge base of small ruminant producers for their success. New approaches and enhancements are needed to improve goat herd health and productivity. We at the Southern University Ag Center have learned a great deal and we understand what is needed to enhance our investigative tools and incorporate new approaches to make small livestock systems work more efficiently.

Traditional veterinary medicine consisting of healing, curing and treating of single animals or entire herds has lost its importance and will more and more be replaced by preventive measures and health management. The key to success in handling animal diseases is early detection. If a disease can be detected in an early phase of its development, the possibility exists that it can be arrested and eliminated before it actually inflicts damage. Early detection presupposes that there is a surveillance system in place that will bring infection to light when it is first seen. Veterinarians, agricultural professionals and producers are then able to manage the problem before it becomes uncontrollable, thus protecting the local livestock industry and ensuring food security for those closely dependent upon livestock. Early detection enables early warning and an early reaction.

\section{Goat Industry}

The USDA defines a small farm with $\$ 250000$ or less in farm sales. In Louisiana $84.5 \%$ of the sales is $\$ 50,000$ or less and only $6.7 \%$ of the farms have $\$ 500,000$ or more in sales. Until recently, the meat goat industry was the fastest growing class of livestock in the U.S.A. The number of meat goat farms almost doubled from 63,000 in 1997 to about 123,000 in 2007 but declined to 100,910 in 2012 [1-3]. There were about 2,550,000 meat goats in 2009, a 23\% increase since 2002 [4]. More than 71\% of the U.S. meat goat population is in the South [5]. Most of the recent growth in the goat industry has occurred in Hawaii, Oklahoma, Louisiana, New Mexico and Idaho [1,2,4,6]. According to the Louisiana Agricultural Summary (2008) for the period between 1998 and 2008 , the number of does increased from about 4,000 to 16,700, and goat producers increased from 400 to over 1,200 [7].

As an indicator of goat meat consumption, more than 10,763,842 million kg of frozen goat meat was imported from Australia and New Zealand into the U.S. in 2008. Concurrently, the domestic harvest of goats in federal and state plants in the US has also increased with more than 670,709 head in federally inspected and 195,100 head in other (state-inspected) plants [5]. 
For the period between 1997 to about 2007, the number of goats sold increased from 533,000 to $1,235,000$, an increase of $232 \%$. Income from goat sales as a fraction of gross animal farm income in Louisiana averaged $\$ 1.35 / \$ 1,000$.

Parasites in goats or lack of control therein, are forcing some goat producers to re-think about possible diversification to or inclusion of lamb production in their operations. As of Jan. 1, 2013, there were 5.3 million head of sheep in the United States. Forty-five percent (2.4 million) of these sheep are located in Texas, California, Colorado, Wyoming and Utah. In 2012, there were 80,000 sheep operations in the United States. The five states with most sheep operations are Texas $(8,700)$, Arizona (5,000), California $(4,100)$, Pennsylvania $(3,800)$ and Iowa $(3,500)$. The number of sheep producers in Louisiana ranged from high of 330 in 2010 to a low of 208 in 2014 [8]. The corresponding number for goats was 876 and 596, respectively. The number of breeding ewes fluctuated from 2449 to 3835 between 2010 and 2014. Does numbers decreased from 14,242 in 2010 to 6578 in 2014. Much of the decline could be contributed to parasite and foot rot problems. Total farm value for sheep was $\$ 2.6$ million as compared to $\$ 3.3$ million for goats. Sheep and goats account for only $0.10 \%$ of all income derived from livestock in Louisiana.

Economic evaluations have shown that major losses due to parasitism have been associated with decreased animal production, cost of prevention and treatment, and ultimately death of infected animals $[9,10]$. In Ghana, the average producer loses up to $34 \%$ of their small ruminant herd to diseases per year [11]. For a small farmer with an average size herd of 50 animals, this represents a significant loss of more than 15 animals per year. Considerable costs may be incurred in controlling animal diseases, though the control measures paid for may not always be effective. This is particularly true for small farmers, who often lack information and have limited diagnostic data to make disease-control and treatment decisions. The US livestock industry generates $\$ 100$ billion annually. Serious economic impacts are expected if animal diseases are introduced, prevalent or suspected.

\section{Importance of Disease Surveillance}

Disease surveillance will help determine the most important diseases in farm operations and will present clinical approaches that can improve detection, diagnosis, and treatment of herd-based problems [12]. Surveillance is the primary key to effective disease management. For small farmers, gastrointestinal nematodes, foot rot, and caseous lymphadenitis (CL) are a huge production limiting problem.

Because of warm, humid conditions during the summer months, GINs are the greatest health and production challenge for goats in southeastern states $[12,13]$. Of the GINs, $H$. contortus is the most detrimental because of substantial economic losses. $H$. contortus or barber pole worm thrives in warm, humid climates and is a voracious blood feeder that can cause anemia and death to the animal if left untreated. Over the past few decades, chemical anthelmintics were used to control GINs. Recently, GINs have developed resistance to most anthelmintics, and now reliance on anthelmintics is nearly impossible.

Foot rot is a costly disease for both sheep and goat producers due to animal weight loss, low fleece weight, decreased milk and reproductive capabilities, premature culling, and increased labor and treatment costs. This infection is prevalent in the Southern regions where there are prolonged periods of warmth and wetness [14]. When pastures have been consistently wet with no dry spells there can be a higher incidence. It can be prevented through concentrated management [14].

Transmission of CL can be spread in high density stocking areas including barns and dry lots [14]. This organism can survive for extended periods in dark, damp areas, soil, and manure [15-17]. Because CL is not considered a reportable disease in the United States there is very little information available about its prevalence

A study by van Leuken, et al., reported that hotspots (areas most likely to contain the actual source) could be identified during the early outbreak stages based on the earliest 2-10\% of the case notifications in Q fever outbreaks in the Netherlands [18]. Distances between the hotspots and suspected goat farms varied from 300-1500 m. In regional likelihood rankings that included all large dairy farms, the suspected goat farms consistently ranked first. The model they developed identified the most likely location of sources in an airborne pathogen outbreak area, even at early stages. This model can help to reduce the number of potential sources to be investigated by microbial testing, and allow rapid implementation of interventions to limit the number of human infections and reduce the risk of source-to-source transmission.

\section{Herd Investigation}

A systematic herd investigation strategy for disease management is pivotal to define the problems, understand important risk factors, develop a plan, and make accurate recommendations for disease management. An initial survey of the goat operation should be conducted to evaluate the herd health practices in place and the existing knowledge of the farmer concerning the control of diseases.

A review of records, feeding routines, housing, routine procedures, vaccination, and treatment protocols begins the investigation and determines which diagnostic procedures and testing strategies are most useful for an operation. The degree of prevalence of gastrointestinal nematodes, foot rot, and CL on goat farms should be determined. This is determined by the collection of on farm samples and analysis. Farm samples should include fecal, blood, aspirates of any intact abscesses, forage and soil samples, along with equipment. 
Disease management is most effective when the problem source is well defined and the exposure can be limited. Screening examinations performed regularly or done at strategic times improves detection of disease and can be used to monitor treatment outcomes, and can avoid disease outbreaks.

\section{Biosecurity}

National and state agencies and institutions have identified bio-security related to animal agriculture as a matter of high priority [19]. To keep illness out of an operation, goat producers are encouraged to maintain biosecurity standards in their operations. Biosecurity (biological safety and well-being) is the set of management practices that prevent infectious diseases from being carried into a herd. Effective biosecurity management practices prevent the spread of disease by minimizing movement of biological organisms and their vectors onto and within the premises. These management practices are based on the principle that it is easier to prevent disease than it is to treat or react to a problem caused by disease. The advantages of adopting a biosecurity program are numerous. An effective program can improve the cost-efficiency of the farm, improve the reputation of the producer, and allow the producer to better maintain the health status of the herd [20].

\section{Conclusion}

Small scale farms face the greatest challenge to generate sufficient income. Diseases affecting livestock can have a significant impact on animal productivity and production, on trade in live animals, meat and other animal products, on human health zoonosis, and, consequently, on the overall process of economic development. Effective approaches to mitigate production limiting diseases will enable these goat farms to thrive and improve their niche markets by helping with disease surveillance and implementation of farm specific herd health management strategies. Quantification of disease populations on these farms through herd investigation and early detection can help with risk assessment and development of risk management strategies needed to control the colonization of these pathogens within goat operations.

\section{References}

1. National Agricultural Statistics Service (NASS) (2009b) Sheep and Goats. Washington, DC: United States Department of Agriculture.

2. National Agricultural Statistics Service (NASS) (2014a) 2012 Census of Agriculture, United States, Summary and State Data, Geographic Area Series, Part 51. Washington, DC: United States Department of Agriculture.

3. National Agricultural Statistics Service (NASS) (2007) Overview of the U.S. sheep and goat industry. Mt An 8-7 (9-07) released September 28, 2007, Washington, DC: United States Department of Agriculture.

4. National Agricultural Statistics Service (NASS) (2009a) Census of Agriculture. United States Summary and State Data. Volume 1 Geographical Area series Part 51. Washington, DC: United States Department of Agriculture.

5. Pinkerton F, McMillin K (2009b) Goat Industry Update Part 2. Goat Rancher, 13-14, 16, 18-19.

6. National Agricultural Statistics Service (NASS) (2014b) Sheep and Goats Final Estimates 2009-2013. Washington, DC: United States Department of Agriculture.

7. LA Agricultural Summary (2008) Louisiana Summary: Agriculture and Natural Resources. LSU AgCenter, Baton Rouge, Louisiana.

8. Jones KG (2014) Trends in the US sheep industry. USDA. ERS. Agric. Info Bul \# 787.

9. McLeod RS (1995) Costs of major parasites to the Australian livestock industries. International J Parasitol 25: 1363-7.

10. Perry BD, Randolph TF (1999) Improving the assessment of the economic impact of parasitic diseases and of their control in production animals. Vet Parasitol 84: 145-68.

11. Baah J, Tuah AK, Addah W, Tait RM (2012) Small ruminant production characteristics in urban households in Ghana. Livestock Research for Rural Development $24(5)$.

12. Marshall RW (2011) Herd-Health Programs for Limited-Resource Farmers: Prevention Versus Treatment. J Extension 49: 5COM2.

13. Kaplan RM, Burke JM, Terrill TH, Miller JE, Getz WR, et al. (2004) Validation of the FAMACHA eye color chart for detecting clinical anemia in sheep and goats on farms in the southern United States. Vet Parasitol 123: 105-20.

14. Pugh DG (2002) Sheep and goat medicine. Bacterial Diseases: Caseous Lymphandenitis. Diseases of the foot: Infectious foot rot.

15. Smith MC, Sherman DM (1994) Subcutaneous swellings. Pages 45-61 in Goat Medicine. Lippincott Williams \& Wilkins, Philadelphia, PA.

16. Williams LH (2001) Caseous lymphadenitis in small ruminants. Vet Clin North Am. Food Anim Pract 17: 359-71.

17. Anderson DE, Rings DM, Pugh DG (2002) Diseases of the integumentary system. Pages 197-222 in Sheep \& Goat Medicine. W. B. Saunders Co., Philadelphia, PA.

18. van Leuken JP, Havelaar AH, van der Hoek W, Ladbury GA, Hackert VH, et al. (2013) A model for the early identification of sources of airborne pathogens in an outdoor environment. PLoS One 8: e80412.

19. Smith MH, Meehan CL (2012) Assessment of Bio-Security Risks Associated with 4-H Animal Science Exhibition Practices in California. J Extension 50: 3FEA10.

20. Mobley R, Lyttle-N'guessan C (2009) The Herd Health Handbook for Goat Producers: Biosecurity at the Farm Level. Florida A\&M University. 


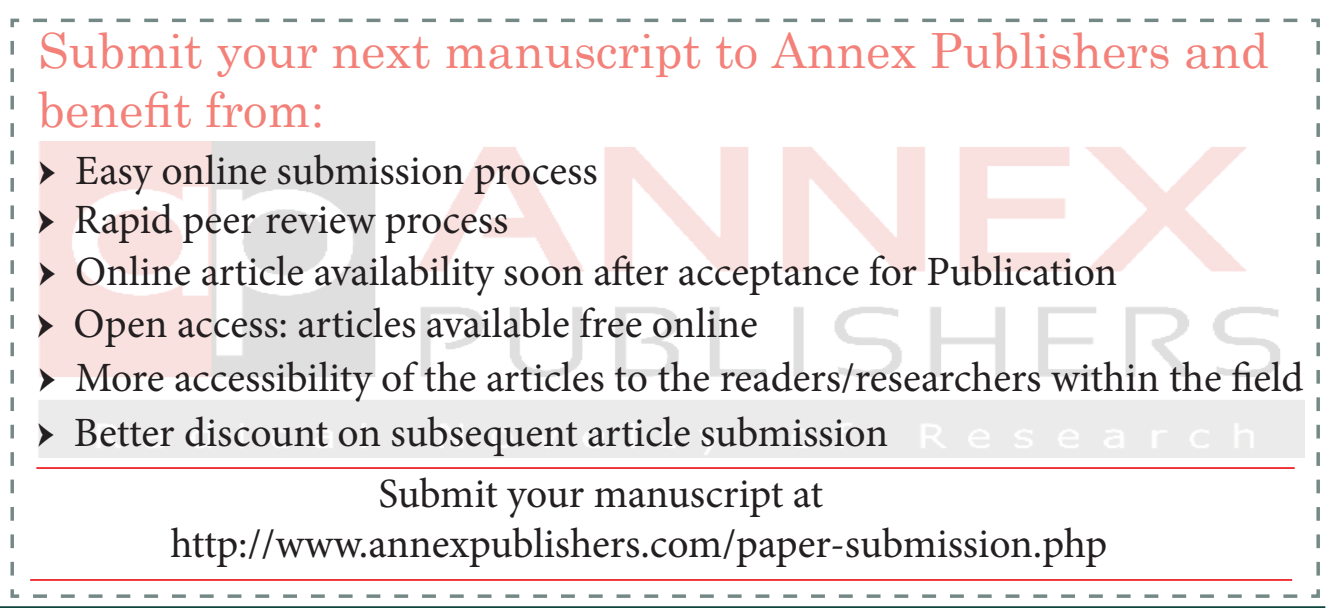

